\title{
Synthesis and characterization of inorganic-organic hybrid gallium selenides
}

Article

Accepted Version

Ewing, S. J. and Vaqueiro, P. (2014) Synthesis and characterization of inorganic-organic hybrid gallium selenides. Inorganic Chemistry, 53 (17). pp. 8845-8847. ISSN 1520-510X doi: https://doi.org/10.1021/ic5011314 Available at https://centaur.reading.ac.uk/37393/

It is advisable to refer to the publisher's version if you intend to cite from the work. See Guidance on citing.

To link to this article DOI: http://dx.doi.org/10.1021/ic5011314

Publisher: American Chemical Society

All outputs in CentAUR are protected by Intellectual Property Rights law, including copyright law. Copyright and IPR is retained by the creators or other copyright holders. Terms and conditions for use of this material are defined in the End User Agreement.

\section{www.reading.ac.uk/centaur}

\section{CentAUR}

Central Archive at the University of Reading

Reading's research outputs online 


\title{
Synthesis and characterization of inorganic-organic hybrid gallium selenides
}

\author{
Sarah J. Ewing ${ }^{\dagger}$ and Paz Vaqueiro ${ }^{\dagger \ddagger^{*}}$ \\ †Institute of Chemical Sciences, Heriot Watt University, Edinburgh, EHı4 4AS, UK. \\ $\ddagger$ Present Address: Department of Chemistry, University of Reading, Whiteknights, Reading, RG6 6AD.
}

Keywords: Solvothermal synthesis, diaminocyclohexane, gallium selenide, inorganic-organic hybrid.

Supporting Information Placeholder

ABSTRACT: Two semiconducting hybrid gallium selenides,
$\left[\mathrm{Ga}_{6} \mathrm{Se}_{9}\left(\mathrm{C}_{6} \mathrm{H}_{14} \mathrm{~N}_{2}\right)_{4}\right]\left[\mathrm{H}_{2} \mathrm{O}\right](1)$ and $\left[\mathrm{C}_{6} \mathrm{H}_{14} \mathrm{~N}_{2}\right]\left[\mathrm{Ga}_{4} \mathrm{Se}_{6}\left(\mathrm{C}_{6} \mathrm{H}_{14} \mathrm{~N}_{2}\right)_{2}\right]$
$(2)$, were prepared using a solvothermal method in the pres-
ence of 1,2-diaminocyclohexane $(1,2-\mathrm{DACH})$. Both materials
consist of neutral inorganic layers, in which 1,2-DACH is co-
valently bonded to gallium. In (1), the organic amine acts as a
monodentate and a bidentate ligand, while in (2) bidentate
and uncoordinated 1,2-DACH molecules coexist.

Condensed gallium chalcogenides, prepared by conventional solid-state synthesis, have been the subject of numerous studies, owing to their interesting semiconducting and non-linear optical properties. ${ }^{1}$ By contrast, the development of microporous and hybrid gallium chalcogenides, especially selenides and tellurides, is still in its early stages. Solvothermal synthesis has been successfully exploited for the preparation of gallium sulfide and selenide frameworks consisting of corner-linked supertetrahedral clusters. ${ }^{2}$ These framework materials exhibit high surface areas, ion-exchange capacity, and photoluminescence. In the case of gallium sulfides, organic amines can act as linkers between supertetrahedral clusters, leading to the formation of a variety of hybrid onetwo- and three-dimensional covalent networks. ${ }^{3}$ Supertetrahedral clusters appear to be less prevalent in gallium selenide chemistry, and the formation organically-functionalised tetrahedral clusters has not been reported to date. Moreover, solvothermally-prepared gallium selenides in which amines are covalently bonded to the anionic network are extremely rare, with only one example known, $[\mathrm{enH}]\left[\mathrm{Ga}_{4} \mathrm{Se}_{7}(\mathrm{en})_{2}\right]{ }^{4}$ Here we report the crystal structure (Table 1) and optical properties of two hybrid gallium selenides, $\left[\mathrm{Ga}_{6} \mathrm{Se}_{9}\left(\mathrm{C}_{6} \mathrm{H}_{14} \mathrm{~N}_{2}\right)_{4}\right]\left[\mathrm{H}_{2} \mathrm{O}\right](1)$ and $\left[\mathrm{C}_{6} \mathrm{H}_{14} \mathrm{~N}_{2}\right]\left[\mathrm{Ga}_{4} \mathrm{Se}_{6}\left(\mathrm{C}_{6} \mathrm{H}_{14} \mathrm{~N}_{2}\right)_{2}\right]$ (2), which were prepared under solvothermal conditions (see Supporting Information), in the presence of 1,2diaminocyclohexane (1,2-DACH). The ability of this amine to act as a chelating ligand leads to markedly different products to those previously found by us when using the 1,4- diaminocyclohexane isomer. $^{5}$

The crystal structure of $\left[\mathrm{Ga}_{6} \mathrm{Se}_{9}\left(\mathrm{C}_{6} \mathrm{H}_{14} \mathrm{~N}_{2}\right)_{4}\right]\left[\mathrm{H}_{2} \mathrm{O}\right]$ (1) (Table 1) contains four crystallographically-independent gallium atoms (Figure 1), found in either solely inorganic $\mathrm{GaSe}_{4}$ tetrahedra, or in hybrid tetrahedra, $\mathrm{GaSe}_{3} \mathrm{~N}$ and $\mathrm{GaSe}_{2} \mathrm{~N}_{2}$, in which 1,2-DACH acts as a monodentate or bidentate ligand respectively. Ga-Se distances range from 2.3148(10) to 2.4233(9) A which are comparable to Ga-Se distances in gallium selenides in the literature, ${ }^{4}$ whilst Ga-N distances, which range from 2.018(12) to 2.030(6) A, are significantly shorter than the Ga-Se distances.

Table 1: Crystallographic Data for (1) and (2)

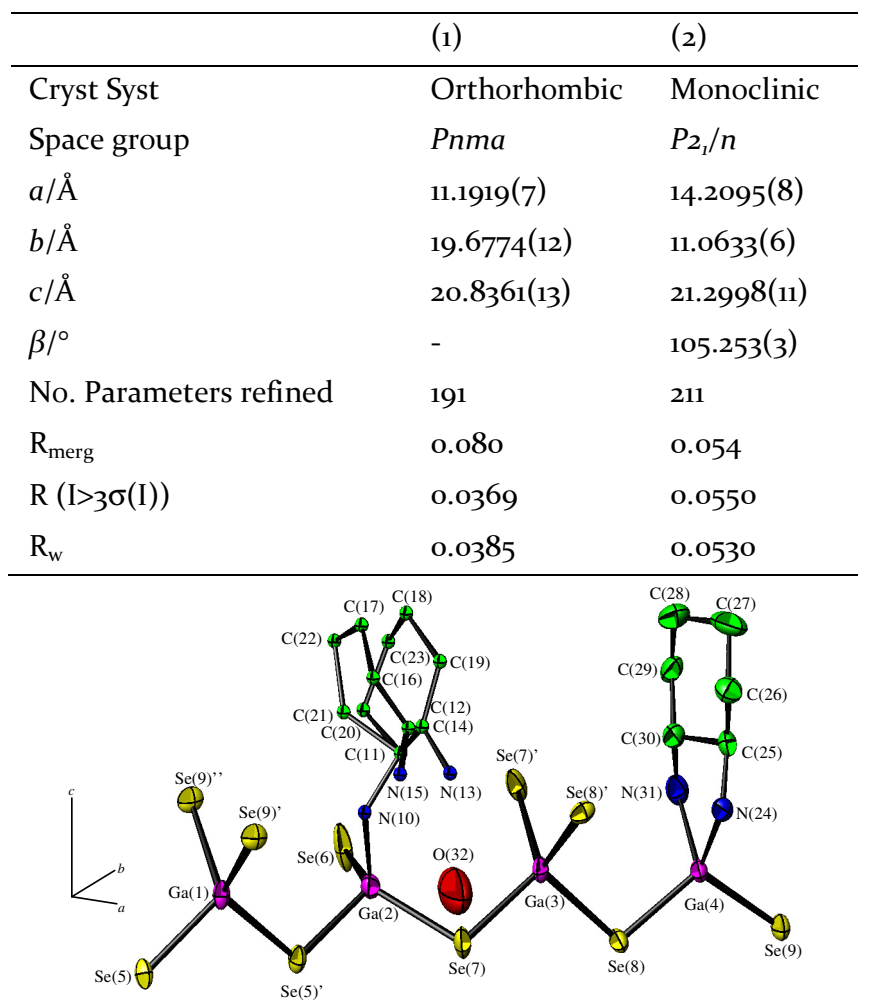

Figure 1: Local coordination diagram for (1) showing the atom labeling scheme and ellipsoids at 50\% probability.

The structure of (1) contains chains of vertex-sharing tetrahedra, in which $\mathrm{GaSe}_{4}$ tetrahedra alternate with $\mathrm{GaSe}_{3} \mathrm{~N}$ and $\mathrm{GaSe}_{2} \mathrm{~N}_{2}$ tetrahedra. Cross-linking of these chains through the terminal selenium atoms results in the for- 
mation of layers containing eight- and six-membered rings (Figure 2(a)). These layers, which are neutral, are aligned parallel to the (oo1) plane, and arranged in a back-to-back stacking sequence (Figure $2(\mathrm{~b})$ ), with the ligands rotated by ca. $90^{\circ}$ on opposite sides of consecutive layers. (a)

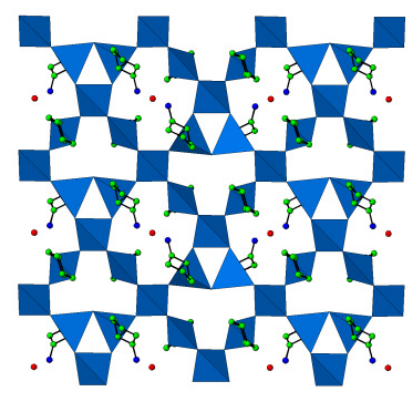

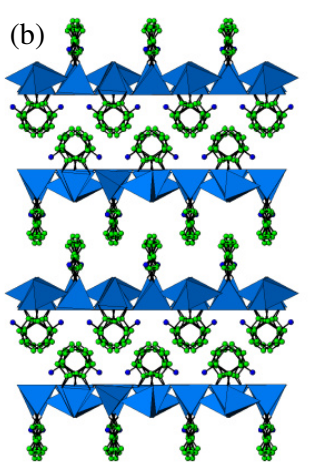

Figure 2: View of (a) a $\left[\mathrm{Ga}_{6} \mathrm{Se}_{9}\left(\mathrm{C}_{6} \mathrm{H}_{14} \mathrm{~N}_{2}\right)_{4}\right]$ layer along [oo1], and (b) the crystal structure of (1) along [210].

The monodentate 1,2-DACH ligand is disordered over two positions, which correspond to the cis- and trans-isomers (Figure 1). The cis-isomer is dominant with a $65(1) \%$ occupancy compared to 35(1)\% for the trans-isomer. A water molecule is located inside each eight-membered ring, and the distances between non-coordinating amine groups and water (N(13)cis-O 2.75(4) $\mathrm{A}, \mathrm{N}(15)$ trans-O 2.6o(3) $\AA$ ), are consistent with the presence of hydrogen bonding interactions.

The structure of $\left[\mathrm{C}_{6} \mathrm{H}_{14} \mathrm{~N}_{2}\right]\left[\mathrm{Ga}_{4} \mathrm{Se}_{6}\left(\mathrm{C}_{6} \mathrm{H}_{14} \mathrm{~N}_{2}\right)_{2}\right]$ (2) contains neutral $\left[\mathrm{Ga}_{4} \mathrm{Se}_{6}\left(\mathrm{C}_{6} \mathrm{H}_{14} \mathrm{~N}_{2}\right)_{2}\right]$ layers, in which 1,2-DACH acts as a bidentate ligand. These layers are composed of chains of alternating $\mathrm{GaSe}_{4}$ and $\mathrm{GaSe}_{2} \mathrm{~N}_{2}$ tetrahedra (Figure 3). In these tetrahedra, Ga-Se distances lie over the range 2.3108(13) to 2.4203(11) $\AA$, while Ga-N distances range from 2.016(7) to 2.040(7) A. These are comparable to values in the literature, ${ }^{4}$ and to those found for (1).

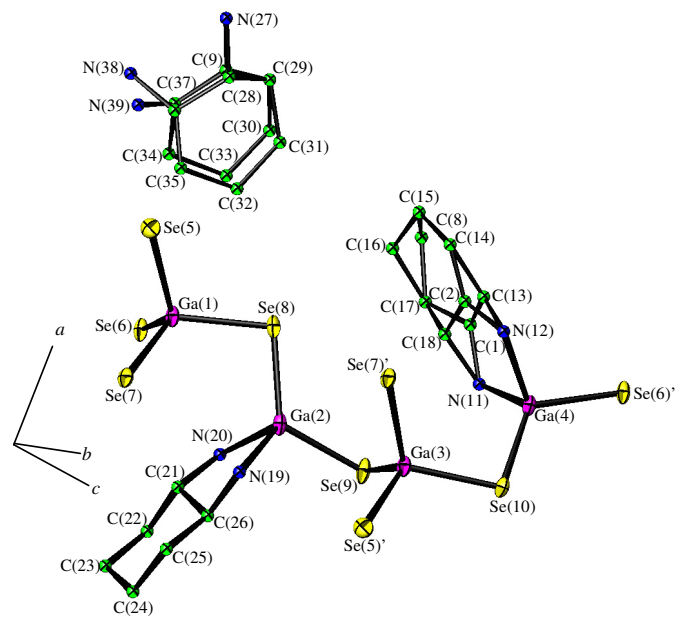

Figure 3: Local coordination diagram for (2) showing the atom labeling scheme and ellipsoids at $50 \%$ probability.

Within a given a chain, the $\mathrm{GaSe}_{4}$ and $\mathrm{GaSe}_{2} \mathrm{~N}_{2}$ tetrahedra are linked by their corners. Additional edge-sharing linkages through the terminal $\mathrm{Se}(5)$ and $\mathrm{Se}(7)$ create layers, which contain six- and fourteen-membered rings (Figure 4(a)). The inorganic component of the layer has a sinusoidal-wave shape, while the bidentate 1,2-DACH ligands are oriented towards the outer part of the layers. The layers are stacked in an $\mathrm{AB}$ repeating sequence, with additional 1,2-DACH moieties located between the layers. As the layers are neutral, protonation of the uncoordinated 1,2-DACH molecules is not required. Both cis- and trans- isomers are present in the crystal structure. The interlayer $1,2-\mathrm{DACH}$ is a $51(2): 49(2)$ cis:trans mixture, whilst the bidentate 1,2-DACH bonded to $\mathrm{Ga}(4)$ is a $41(2): 59(2)$ cis:trans mixture. The N-H...Se distances between the non-coordinating 1,2-DACH and the layers (e.g. N(27)-Se(9) 3.501(7) Å) imply the presence of hydrogen bonding interactions.

Infrared spectra (Supporting information) of (1) and (2) are consistent with the presence of 1,2-DACH. Stretches at 3138 and $3204 \mathrm{~cm}^{-1}$ for (1) and (2) respectively can be assigned to the N-H symmetric stretch of the $-\mathrm{NH}_{2}$ groups. Peaks at 2962 and $2897 \mathrm{~cm}^{-1}$ for (1) and (2) were assigned to C-H stretches. C-N stretching vibrations are observed at 1396 and $1378 \mathrm{~cm}^{-1}$ for (1) and (2). (a)

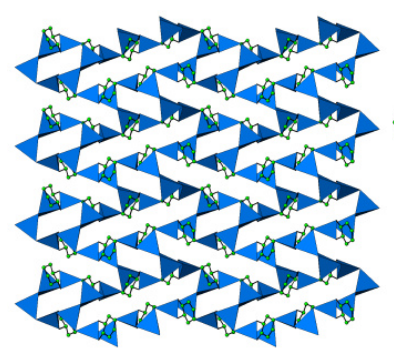

(b)

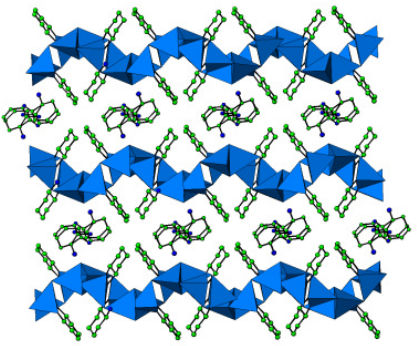

Figure 4: View of (a) a layer of (2) along [301], and (b) the crystal structure of (2) along [010].

Thermogravimetric analysis (TGA) (Supporting information) under an oxidising atmosphere shows that (1) and (2) are stable up to $c a .150^{\circ} \mathrm{C}$ and $200^{\circ} \mathrm{C}$ respectively. Decomposition of the materials occurs in two steps. A $\sim 20 \%$ weight loss is observed for the initial decomposition step of (1). This loss could be attributed to the loss of water and monodentate 1,2-DACH (calculated loss of $15.5 \%$ ). The overall weight loss is $65.1 \%$, in excellent agreement with the calculated weight loss of $64.9 \%$ for the decomposition of (1) to $\mathrm{Ga}_{2} \mathrm{O}_{3}$. The first decomposition step of (2), $26.2 \%$, can be attributed to the loss of the 1,2-DACH moieties (calc. 31.3\%). Total loss of $59.9 \%$ is in reasonable agreement with the decomposition of $\left[\mathrm{C}_{6} \mathrm{H}_{14} \mathrm{~N}_{2}\right]\left[\mathrm{Ga}_{4} \mathrm{Se}_{6}\left(\mathrm{C}_{6} \mathrm{H}_{14} \mathrm{~N}_{2}\right)_{2}\right]$ to $\mathrm{Ga}_{2} \mathrm{O}_{3}$ (calc. $65.8 \%$ ).

The UV-vis optical absorption spectra of (1) and (2) are shown in Figure 5. The estimated band gaps are 2.36(2) eV for compound (1) and 2.30(6) eV for (2), larger than those found for the bulk selenides $\mathrm{Ga}_{2} \mathrm{Se}_{3}(2.1 \mathrm{eV})$ and $\mathrm{GaSe}(1.97$ $\mathrm{eV}) .{ }^{6}$ For solvothermally-prepared antimony sulphides, it has been found that an increase in framework density leads to a decrease in the optical band gap. ${ }^{7}$ This correlation also seems to hold here, given that (1) and (2) have larger band gaps than the corresponding condensed phases. This is consistent with DFT calculations on a related layered hybrid selenide, [CdSe(hda) $\left.)_{0.5}\right]$ (hda = 1,6-hexanediamine), which show that the electronic band-edge states are dominated by the inor- 
ganic layers, and that the conduction and valence bands are narrower than in bulk CdSe, resulting in a larger band gap. ${ }^{8}$

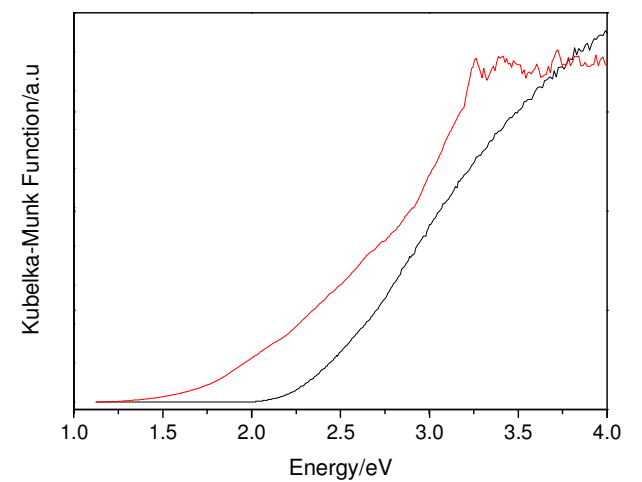

Figure 5: Optical absorption spectra of (1) (black line) and (2) (red line).

An unusual feature of (1) and (2) is the presence of an organic amine covalently bonded to a main-group metal centre. In solvothermally-prepared main-group chalcogenides, the organic amines are normally incorporated into the crystal structure as countercations, and bonded through electrostatic and weak hydrogen bonding interactions. ${ }^{9}$ Gallium however has a higher acid character than other main-group elements, and this favours bonding with hard bases, in this case the organic amine. Covalently-bonded amines have been previously found in gallium sulfides ${ }^{3}$ and in [enH] $\left[\mathrm{Ga}_{4} \mathrm{Se}_{7}(\mathrm{en})_{2}\right] .^{4}$ In the heavier tellurides, amines have been found to form covalent bonds to indium, as exemplified by $\left[\mathrm{M}(\text { phen })_{3}\right]_{2}\left[\operatorname{In}_{18} \mathrm{Te}_{30}(\text { dapn })_{6}\right] \cdot 2 \mathrm{Hdapn} \cdot$ dapn $(\mathrm{M}=\mathrm{Fe}(\mathrm{II})$, and $\mathrm{Ni}(\mathrm{II})$, dapn $=1.3$-diaminepropane $),{ }^{10}$ $\left[\mathrm{Mn}(\mathrm{DACH})_{3}\right]_{2}\left[\mathrm{In}_{18} \mathrm{Te}_{30}(\mathrm{DACH})_{6}\right]\left[\mathrm{DACHH}_{2}\right]\left[\mathrm{H}_{2} \mathrm{O}\right]^{11}$ and $\left[\operatorname{In}(\mathrm{en})_{3}\right]\left[\operatorname{In}_{5} \mathrm{Te}_{8}(\mathrm{en})_{2}\right] \cdot 0$. en. $^{12}$ This suggests that for Group 13 elements, the relative stabilities of the metal-chalcogen and metal-nitrogen bonds under solvothermal conditions are finely balanced.

The hybrid gallium selenides reported here can be considered to be related to the family of II/VI hybrid semiconductors, which have the general formula $\left[\mathrm{MQ}(\mathrm{L})_{\mathrm{x}}\right](\mathrm{M}=\mathrm{Mn}, \mathrm{Zn}$, $\mathrm{Cd} ; \mathrm{Q}=\mathrm{S}$, Se, Te; $\mathrm{L}=$ organic amine), and consist of inorganic slabs sandwiched by covalently-bonded organic layers. ${ }^{13}$ These hybrid materials have been found to exhibit remarkable properties, including large band-gap tunability, ${ }^{13}$ broad photoluminescent emission which can result in direct white light emission ${ }^{13(\mathrm{c}),(\mathrm{e})}$ and zero thermal expansion. ${ }^{13(\mathrm{~b})}$ The inorganic slabs of the $\left[\mathrm{MQ}(\mathrm{L})_{\mathrm{x}}\right]$ phases retain the connectivity of the zinc blende or the wurtzite structures found in bulk $\mathrm{II} / \mathrm{VI}$ semiconductors, and consist of corner-sharing $\mathrm{MQ}_{4}$ and $\mathrm{MQ}_{3} \mathrm{~N}$ tetrahedra. By contrast, the inorganic layers in (1) and (2) are not related to the defect zinc blende structure of $\mathrm{Ga}_{2} \mathrm{Se}_{3}$, and contain $\mathrm{GaSe}_{4}, \mathrm{GaSe}_{3} \mathrm{~N}$ and $\mathrm{GaSe}_{2} \mathrm{~N}_{2}$ tetrahedra, which can be vertex- or edged-linked. However, in common with $\left[\mathrm{MQ}(\mathrm{L})_{\mathrm{x}}\right]$ phases, the layers in (1) and (2) are neutral, and held together by weak van der Waals or hydrogen bonding interactions. It has been shown that exfoliation of $\left[\mathrm{MQ}(\mathrm{L})_{\mathrm{x}}\right]$ phases is possible, and results in the creation of freestanding single layers, ${ }^{14}$ which can be considered inorganic graphene analogues. We envisage that exfoliation of (1) and (2) may also be feasible. Our current efforts with hybrid gallium selenides are directed towards the synthesis of addi- tional members of this family and the detailed investigation of their optical properties.

Supporting Information: Experimental procedures, crystallographic data in CIF format, powder X-ray diffraction data, elemental analysis, FTIR and TGA data. This material is available free of charge via the Internet at http://pubs.acs.org.

Corresponding Author: *Email: p.vaqueiro@reading.ac.uk.

\section{ACKNOWLEDGMENT}

SJE would like to thank Heriot Watt University for studentship. The authors would like to thank Christina Graham for elemental analysis data.

\section{REFERENCES}

1 (a) Panich, A.M. J. Phys.: Condens. Matter 2008, 20, 293202; (b) Johnsen, S; Liu, Z.; Peters, J.A.; Song, J.-H.; Peter, S. C.; Malliakas, C. D.; Cho, N. K.; Jin, H.; Freeman, A. J.; Wessels, B. W.; Kanatzidis, M. G. Chem. Mater. 2011, 23, 3120-3128; (c) Fernelius, N.C. Prog. Cryst. Growth Charact. Mater. 1994, 28, 275-353; (d) Tell, B; Kasper, H.M. Phys. Rev. B 1971, 4, 4455-4459; (e) Contreras, M.A.; Egaas, B.; Ramanathan, K; Hiltner, J.; Swartzlander, A.; Hasoon, F.; Noufi, R. Prog. Photovoltaics 1999, 7, 311-316.

2 (a) Zheng, N.; Bu, X.; Wang, B.; Feng, P. Science 2002, 298, 23662369; (b) Zheng, N.; Bu, X.; Feng, P. J. Am. Chem. Soc. 2003, 125, $1138-$ 1139; (c) Vaqueiro, P.; Romero, M. L. J. Phys. Chem. Solids, 20o7, 68, 1239-1243; (d) Wu, T.; Wang, X.; Bu, X.; Zhao, X.; Wang, L.; Feng, P. Angew. Chem. Int. Ed. 2009, 48, 7204-7207.

3 (a) Vaqueiro, P; Romero, M. L. J. Am. Chem. Soc., 20o8, 130, 9630-9631; (b) Vaqueiro, P.; Romero, M. L. Inorg. Chem. 2oo9, 48, 810-812; (c) Vaqueiro, P.; Romero, M. L.; Rowan, B. C.; Richards, B.S. Chem. Eur. J. 2o10, 16, 4462-4465; (d) Wu, T.; Khazhakyan, R.; Wang, L.; Bu, X.; Zheng, S.-T.; Chau, V.; Feng, P. Angew. Chem. Int. Ed. 2011, 50, 2536-2539.

4 Dong, Y.; Peng, Q.; Wang, R.; Li, Y. Inorg. Chem. 2003, 42, 17941796.

5 (a) Ewing, S. J.; Powell, A. V.; Vaqueiro, P. J. Solid State Chem., 2011, 184, 1800-1804; (b) Ewing, S. J.; Romero, M. L.; Hutchinson, J.; Powell, A. V.; Vaqueiro, P. Z. Anorg. Allg. Chem. 2012, 638, 2526-2531.

6 (a) Springford, M. Proc. Phys. Soc. 1963, 82, 1020-1028; (b) Bube, R.H.; Lind E.L. Phys. Rev., 1959, 115, 1159-1164.

7 Powell, A. V.; Lees, R. J.; Chippindale, A. M. J. Phys. Chem. Solids. 2008, 69, 1000-1006.

8 Wei, S.; Lu, J.; Qian, Y. Chem. Mater. 2008, 20, 7220-7227.

9 (a) Sheldrick, W. S; J. Chem. Soc. Dalton Trans. 2000, 3041-3052; (b) Sheldrick, W. S; Wachhold, M; Coord. Chem. Rev. 1998, 176, 211322; (c) Powell, A.V.; Int. J. Nanotechnol. 2011, 8, 783-794.

10 Zhang, X.; Pu, Y-Y.; You, L.-S.; Bian, G-Q.; Zhu, Q-Y.; Dai, J. Polyhedron, 2013, 52, 645-649.

11 Wang, Y-H.; Luo, W.; Jiang, J-B.; Bian, G-Q.; Zhu, Y-Q.; Dai, J. Inorg. Chem. 2012, 51, 1219-1221.

12 Zhang, Q. C.; Chung, I.; Jang, J. I.; Ketterson, J. B.; Kanatzidis, M. G. Chem. Mater., 2009, 21, 12-14.

13 (a) Huang, X.; Li, J.; Fu, H. J. Am. Chem. Soc. 2ooo, 122, 87898790; (b) Zhang, Y.; Islam, Z.; Ren, Y.; Parilla, P.A.; Ahrenkiel, S.P.; Lee, P. L.; Mascarenhas, A.; McNevin, M. J.; Naumov, I.; Fu, H.-X., Huang, X.-Y.; Li, J. Phys. Rev. Lett. 2007, 99, 215901; (c) Ki, W.; Li, J. J. Am. Chem. Soc., 20o8, 130, 8114-8115; (d) Huang, X.; Roushan, M.; Emge, T. J.; Bi, W.; Thiagarajan, S.; Cheng, J.-H.; Yang, R.; Li, J. Angew. Chem. Int. Ed., 20o9, 48, 7871-7874; (e) Ki, W.; Li, J.; Eda, G.; Chhowalla, M. J. Mater. Chem. 2010, 20, 10676-10679; (f) Huang, X.; Li, J. J. Am. Chem. Soc. 2007, 129, 3157-3162.

14 Sun, Y.; Sun, Z.; Gao, S.; Cheng, H.; Liu, Q.; Piao, J.; Tao, T.; Wu, C.; Hu, S.; Wei, S. Nature Commun. 2012, 3, 1057. 
Table of Contents Entry
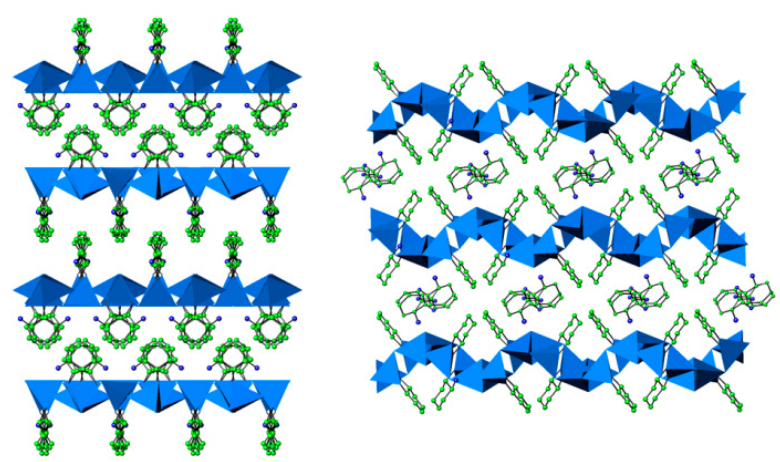

Synopsis:

The synthesis and characterization of two semiconducting hybrid gallium selenides, which consist of neutral inorganic layers covalently bonded to 1,2-diaminocyclohexane, is described. 